\title{
Regulation of Glycosylphosphatidylinositol-Anchored Protein (GPI-AP) Expression by F-Box/LRR-Repeat (FBXL) Protein in Wheat (Triticum aestivum L.)
}

\author{
Min Jeong Hong $\left.{ }^{1}{ }^{(}\right)$, Jin-Baek Kim ${ }^{1} \mathbb{D}$, Yong Weon Seo ${ }^{2}$ and Dae Yeon Kim ${ }^{3, *}$ \\ 1 Advanced Radiation Technology Institute, Korea Atomic Energy Research Institute, 29 Geumgu, \\ Jeongeup 56212, Korea; hongmj@kaeri.re.kr (M.J.H.); jbkim74@kaeri.re.kr (J.-B.K.) \\ 2 Division of Biotechnology, Korea University, 145 Anam-Ro, Seongbuk-Gu, Seoul 02841, Korea; \\ seoag@korea.ac.kr \\ 3 Institute of Animal Molecular Biotechnology, Korea University, 145 Anam-Ro, Seongbuk-Gu, \\ Seoul 02841, Korea \\ * Correspondence: dykim@korea.ac.kr; Tel.: +82-2-3290-4514
}

check for updates

Citation: Hong, M.J.; Kim, J.-B.; Seo, Y.W.; Kim, D.Y. Regulation of GlycosylphosphatidylinositolAnchored Protein (GPI-AP) Expression by F-Box/LRR-Repeat (FBXL) Protein in Wheat (Triticum aestivum L.). Plants 2021, 10, 1606. https://doi.org/10.3390/ plants10081606

Academic Editor: Tae-Hwan Jun

Received: 2 July 2021

Accepted: 2 August 2021

Published: 5 August 2021

Publisher's Note: MDPI stays neutral with regard to jurisdictional claims in published maps and institutional affiliations.

Copyright: (c) 2021 by the authors. Licensee MDPI, Basel, Switzerland. This article is an open access article distributed under the terms and conditions of the Creative Commons Attribution (CC BY) license (https:/ / creativecommons.org/licenses/by/ $4.0 /)$.

\begin{abstract}
F-box proteins are substrate recognition components of the Skp1-Cullin-F-box (SCF) complex, which performs many important biological functions including the degradation of numerous proteins via the ubiquitin-26S proteasome system. In this study, we isolated the gene encoding the F-box/LRR-repeat (FBXL) protein from wheat (Triticum aestivum L.) seedlings and validated that the TaFBXL protein is a component of the SCF complex. Yeast two-hybrid assays revealed that TaFBXL interacts with the wheat glycosylphosphatidylinositol-anchored protein (TaGPI-AP). The green fluorescent protein (GFP) fusion protein of TaFBXL was detected in the nucleus and plasma membrane, whereas that of TaGPI-AP was observed in the cytosol and probably also plasma membrane. yeast two-hybrid and bimolecular fluorescence complementation (BiFC) assays revealed that TaFBXL specifically interacts with TaGPI-AP in the nucleus and plasma membrane, and TaGPI-AP is targeted by TaFBXL for degradation via the $26 \mathrm{~S}$ proteasome system. In addition, TaFBXL and TaGPI-AP showed antagonistic expression patterns upon treatment with indole-3-acetic acid (IAA), and the level of TaGPI-AP was higher in tobacco leaves treated with both MG132 (proteasome inhibitor) and IAA than in leaves treated with either MG132 or IAA. Taken together, our data suggest that TaFBXL regulates the TaGPI-AP protein level in response to exogenous auxin application.
\end{abstract}

Keywords: Triticum aestivum; yeast two-hybrid; F-box protein; SCF complex; TaFBXL; TaGPI-AP

\section{Introduction}

Ubiquitin is a small globular protein composed of 76 conserved amino acid residues, which attach to the target protein to regulate its degradation by the $26 \mathrm{~S}$ proteasome. The plant ubiquitin-proteasome system controls the degradation of numerous proteins and plays an important role in plant growth, hormone signaling, abiotic stress response, embryogenesis, and senescence [1]. The process of ubiquitination is mediated by three enzymes: ubiquitin-activating enzyme (E1), ubiquitin-conjugating enzyme (E2), and ubiquitin ligase (E3). To ubiquitinate the target protein, ubiquitin is activated by E1 via the formation of a thioester bond, and the activated ubiquitin is transferred to E2. Then, E3 recruits the activated ubiquitin from E2 and transfers ubiquitin to the target protein for inducing its proteasomal degradation [2]. Over 6\% of the genes in the Arabidopsis thaliana genome are predicted to encode at least 1400 putative E3 ligases [3,4]. The specificity of target protein degradation is mainly recognized by E3 ligases in a suitable mechanism to respond to environmental alternation, stress response, and regulation of developmental stage during life cycle [5].

CUL1-based E3 ligases or SCF ubiquitin-protein ligases are composed of S-phase kinase-associated protein 1 (Skp1), Cullin 1 (CUL1), F-box protein, and RBX1 [6]. CUL1 
acts as a molecular scaffold that brings together RBX1 (which binds to E2 ligase) and Skp1, which serves as an adapter between the F-box proteins and CUL1 links. F-box proteins mediate the ubiquitination and subsequent proteasome-dependent degradation of target proteins in eukaryotic cells [4]. Due to their role in the recognition of the substrate and its recruitment for degradation by the $26 \mathrm{~S}$ proteasome, F-box proteins show high diversity in plant species. A total of 692, 337, and 779 F-box protein-encoding genes have been identified in Arabidopsis, poplar (Populus spp.), and rice (Oryza sativa L.), respectively, and the plant F-box protein superfamily is divided into 42 families (e.g., FBA, Kelch, leucine-rich repeat (LRR), Tub, WD40, and DUF), which can be distinguished based on the domain organization in the C-terminal region [7]. In plants, F-box protein-mediated ubiquitination and degradation of the target protein are required for the modulation of various developmental and physiological processes, such as seed germination [8], floral organ development [9], abiotic stress response [10,11], plant defense [12-14], and phytohormone signal transduction [15-17].

The plant hormone auxin is involved in many plant processes and is essential for cell elongation, division, and differentiation, and morphogenesis. The mainstream auxin signal transduction in the nucleus is governed by TIR1/AFB F-box proteins [16]. In the nucleus, auxin binds to TIR1/AFB F-box proteins and promotes the degradation of the Aux/IAA transcriptional repressors through the ubiquitin $26 S$ proteasome system by combinational interactions [18]. Moreover, several signaling mechanisms of auxin are suggested to be regulated in the cell membrane by the plant-specific auxin-binding protein 1 (ABP1), which has been proposed to function as an auxin receptor in the cell membrane $[19,20]$. ABP1, a 22-kDa glycoprotein, is essential for a wide variety of auxinregulated processes. A previous study showed that ABP1 plays an important role in clathrin-dependent endocytosis; thus, ABP1 promotes clathrin recruitment for enhancing endocytosis but inhibits the recruitment of clathrin by binding to auxin [21]. Moreover, plasma membrane-localized transmembrane kinases (TMKs) functionally interact with $\mathrm{ABP} 1$ in a complex, thus inducing ABP1 to transmit the extracellular auxin signal to the intracellular rho of plants (ROP) signaling component [22]. In addition, since ABP1 lacks a transmembrane domain, it is necessary for another membrane-bound "docking protein" to bind to the plasma membrane [21]. In maize (Zea mays L.), glycosylphosphatidylinositolanchored protein (GPI-AP) has been identified as a candidate docking protein. It is possible that ABP1 contributes to the directional cell growth processes via the plasma membranelocalized GPI-AP, in a similar way as the C-terminal peptide-binding protein 1 (CBP1), and $\mathrm{CBP}$ family members interact with the C-terminus of ABP1 to facilitate the secretion of auxin $[23,24]$.

The function of F-box proteins in wheat is largely unknown with respect to wheat developmental stages. Recently, Hong et al. (2020) reported on 1796 F-box genes in the wheat genome classified into various subgroups based on their functional C-terminal domains [25]. Furthermore, transcriptome analysis and expression analysis using reverse transcription-quantitative PCR (RT-qPCR) during various wheat developmental stages revealed that some F-box genes were specifically expressed in the vegetative and/or seed developmental stages [25]. Among them, we select and demonstrate that the wheat (Triticum aestivum L.) F-box/LRR-repeat (TaFBXL) protein (TraesCS1B02G275600) interacts with TaGPI-AP both in vivo and in vitro and that TaGPI-AP, which is involved in the response to extracellular auxin to facilitate auxin secretion [23], is degraded by the 26S proteasome. Our results suggest that TaFBXL is a possible regulator of TaGPI-AP in response to exogenous auxin application to facilitate the signaling transduction of the auxin receptor complex.

\section{Materials and Methods}

\subsection{Plant Materials and Growth Conditions}

Wheat (Triticum aestivum L.) cultivar Keumkang (IT 213100) developed by the National Institute of Crop Science (RDA, JeonJu-si, Jeonbuk, Korea) was used in this study. Seeds 
were vernalized and cold stratified at $4{ }^{\circ} \mathrm{C}$ for 4 weeks to facilitate germination and were then transferred to an Incu Tissue $(72 \mathrm{~mm} \times 72 \mathrm{~mm} \times 22 \mathrm{~mm}$; SPL Life Sciences, Gyeonggi-do, Korea) containing a polypropylene net floating on Hoagland solution (SigmaAldrich, Burlington, MA, USA). Then, the seedlings were transferred to pots filled with soil (Sunshine Mix \#1; Sun Gro Horticulture, Agawam, MA, USA) and grown in a greenhouse under controlled conditions $\left(25^{\circ} \mathrm{C}\right.$ day $/ 20{ }^{\circ} \mathrm{C}$ night temperature, $16 \mathrm{~h}$ light $/ 8 \mathrm{~h}$ dark photoperiod, and $600 \mu \mathrm{mol} \mathrm{m} \mathrm{m}^{-2} \mathrm{~s}^{-1}$ light intensity). Plant samples were collected at different developmental stages, determined according to the Zadoks growth scale [26]: leaf at Z13 (three leaves emerged; Stage 1), leaf at Z24 (main stem and four tillers; Stage 2), leaf at Z51 (leaf at the tip of ear just visible, booting stage; Stage 3), spikelets at Z61 (beginning of anthesis; Stage 4), spikelets at Z73 (early milk development; Stage 5), spikelets at Z83 (early dough; Stage 6), and spikelets at Z91 (hard grain; Stage 7). To determine the effect of abiotic stress on TaFBXL expression at the fully expanded 3rd leaf stage (Zadok scale 13 ), seedlings were sprayed with $100 \mu \mathrm{M}$ of indole-3-acetic acid (IAA) mixed with $0.2 \%$ Tween 20 ( $1 \mathrm{~mL}$ per plant) [27,28]. Then, seedlings were collected at $0,2,6$, and $12 \mathrm{~h}$ after the spray treatment and stored at $-80^{\circ} \mathrm{C}$ until needed for RNA extraction.

\subsection{Gene Cloning and Gene Expression Analysis}

Total RNA was extracted from each sample using TRIzol reagent (Invitrogen, Waltham, MA, USA) and was treated with DNase I (New England Biolabs, MA, USA) to remove any traces of contaminating DNA. First-strand cDNA was synthesized from $1 \mu \mathrm{g}$ of total RNA using a Power cDNA Synthesis Kit (iNtRON Biotechnology, Gyeonggi-do, Korea). Full-length coding sequences (CDSs) of TaFBXL (TraesCS1B02G275600), TaGPI-AP (TraesCS2D02G145400), and TaABP1 (TraesCS5A02G098900) genes were amplified using gene-specific primer sets designed on the basis of the wheat reference sequence (version 45) available at Ensembl Plant (https://plants.ensembl.org/index.html, accessed 20 March 2020) (Table S1). PCR for gene isolation was performed under the following thermocycling conditions: initial denaturation at $94{ }^{\circ} \mathrm{C}$ for $10 \mathrm{~min}$, followed by 31 cycles of denaturation at $94^{\circ} \mathrm{C}$ for $1 \mathrm{~min}$, annealing at a gene-specific temperature for $2 \mathrm{~min}$, and elongation at $72{ }^{\circ} \mathrm{C}$ for $1 \mathrm{~min}$, and a final extension at $72{ }^{\circ} \mathrm{C}$ for $5 \mathrm{~min}$. PCR products were cloned into the $\mathrm{pCR} 8 / \mathrm{GW} / \mathrm{TOPO}$ cloning vector (Thermo Fisher Scientific, Waltham, MA, USA) and sequenced. The amino acid sequence of TaFBXL was analyzed using InterProScan (https:/ / www.ebi.ac.uk/interpro/search/sequence-search, accessed 15 April 2020).

To analyze gene expression analysis, RT-qPCR was performed in a 48-well plate (Eco Real-Time PCR System, Illumina, San Diego, CA, USA) using $1 \mu \mathrm{L}$ of reverse-transcribed cDNA and $2 \times$ TB Green Premix Ex Taq II (Tli RNaseH plus; Takara, Kusatsu, Shiga, Japan). The RT-qPCR cycling conditions were as follows: initial denaturation at $95{ }^{\circ} \mathrm{C}$ for $5 \mathrm{~min}$, followed by 40 cycles of denaturation at $95^{\circ} \mathrm{C}$ for $10 \mathrm{~s}$ and annealing and extension at $65^{\circ} \mathrm{C}$ for $30 \mathrm{~s}$. Three biological replicates of cDNA from every single plant and spikelet in Stage 1-4 and Stage 5-7 stage, respectively, were used for RT-qPCR experiments. Additionally, the Actin (AB181991) gene was used as an endogenous control for relative quantification (RQ) of TaFBXL expression. RQ is a fold change in each sample, compared to the calibrator (Stage 1), which has an RQ value of 1 . Standard curves were prepared for both the target and endogenous reference. For each experimental sample, the amount of target and endogenous reference was determined from the appropriate standard curve. Then, the target amount was divided by the endogenous reference amount to obtain a normalized target value. Each normalized target value was divided by that of the calibrator to generate the relative expression levels. The primer sets for RT-qPCR are listed in Table S1.

\subsection{Yeast Two-Hybrid (Y2H) Assay and Library Screening}

A wheat (T. aestivum L.) cDNA library was constructed for $\mathrm{Y} 2 \mathrm{H}$ screening. Total RNA was extracted from leaves at Z13 (Stage 1) using the TRIzol reagent. Then, a wheat cDNA library was constructed from $2 \mu \mathrm{g}$ total RNA using the Make Your Own Mate \& 
Plate $^{\mathrm{TM}}$ Library System (Clontech, Takara, Kusatsu, Shiga, Japan), according to the manufacturer's protocol. All colonies were pooled with the freezing medium (YPD agar medium with $25 \%$ glycerol), and $1 \mathrm{~mL}$ aliquots of the cDNA library were stored at $-80{ }^{\circ} \mathrm{C}$. To perform the $\mathrm{Y} 2 \mathrm{H}$ screen, the full-length coding sequence (CDS) of TaFBXL was cloned into the pGBKT7-GW vector (bait) using the Gateway LR recombination reaction (Thermo Fisher Scientific, Waltham, MA, USA). The pGBKT7-TaFBXL was transformed into yeast (Saccharomyces cerevisiae) strain Y2HGold using the Matchmaker Gold Y2H System (Clontech, Takara, Kusatsu, Shiga, Japan), according to the manufacturer's protocol. Y2HGold cells harboring bait vector were maintained in minimal synthetic defined (SD) medium lacking tryptophan (SD/-Trp). Then, bait strain and cDNA library (prey) were mixed and incubated at $30^{\circ} \mathrm{C}$ with shaking at 30-50 rpm for 20-24 h. The mating cultures were spread onto plates containing double dropout (DDO) SD medium lacking leucine (Leu) and $\operatorname{Trp}(\mathrm{SD} /$-Leu/-Trp) but containing X-alpha-galactosidase (X- $\alpha$-Gal) and Aureobasidin A $(\mathrm{AbA})(\mathrm{DDO} / \mathrm{X} / \mathrm{A})$. Colonies appeared after approximately $5-7$ days and were transferred to quadruple dropout medium (SD/-adenine [Ade]/-histidine [His]/-Leu/-Trp) supplemented with $\mathrm{X}-\alpha-\mathrm{Gal}$ and $\mathrm{AbA}(\mathrm{QDO} / \mathrm{X} / \mathrm{A})$. Colonies that grew on $\mathrm{QDO} / \mathrm{X} / \mathrm{A}$ plates were considered as candidates representing positive interactions between bait and prey proteins. Yeast colony PCR using Matchmaker Insert Check PCR Mix 2 (Clontech, Takara, Kusatsu, Shiga, Japan) was performed to select positive clones. The selected prey plasmids were rescued using the Easy Yeast Plasmid Isolation Kit (Clontech, Takara, Kusatsu, Shiga, Japan). The prey inserts were sequenced and annotated using the National Center for Biotechnology Information GenBank database.

\subsection{Co-Transformation and $\beta$-Galactosidase ( $\beta$-Gal) Activity Assay}

CDSs of TaFBXL, TaGPI-AP, and TaABP1 were cloned into the pGBKT7 vector using the Gateway system [29]. Using the lithium acetate method, each of the TaFBXL, TaGPI-AP, and $T a A B P 1$ constructs was co-transformed into the yeast strain AH109, along with one of six TaSKP (TaSKP1-TaSKP6) CDSs previously cloned into the $\mathrm{pCR} 8 / \mathrm{GW} / \mathrm{TOPO}$ vector (Thermo Fisher Scientific, MA, USA) [30]. Transformants were plated onto SD/-Leu/-Trp or SD/-Ade/-His/-Leu/-Trp, supplemented with X- $\alpha$-Gal to detect prey-bait interactions. AH109 cells co-transformed with SV40 large T antigen (pGADT7-T) and p53 (pGBKT7-53) and AH109 cells co-transformed with SV40 large T antigen (pGADT7-T) and Lamin-C (pGADT7-Lam) were used as positive and negative controls, respectively.

To validate the strength of a protein-protein interactions, quantitative $\beta$-Gal activity was assayed using 2-nitrophenyl $\beta$-D-galactopyranoside (ONPG; Sigma) as a substrate, according to the Clontech yeast protocols handbook (protocol no. PT3024-1). Yeast cells were grown overnight at $30{ }^{\circ} \mathrm{C}$ in SD selective medium. Then, $2 \mathrm{~mL}$ of the cell culture was added to $8 \mathrm{~mL}$ of yeast extract peptone dextrose (YPD) media, and the culture was grown until the optical density of the culture at $600 \mathrm{~nm}\left(\mathrm{OD}_{600}\right)$ reached 0.8 . Thereafter, yeast cells were centrifuged and re-suspended in Z-buffer $\left(60 \mathrm{mM} \mathrm{Na} 2 \mathrm{HPO}_{4}, 40 \mathrm{mM}\right.$ $\mathrm{NaH}_{2} \mathrm{PO}_{4}, 10 \mathrm{mM} \mathrm{KCl}$, and $1 \mathrm{mM} \mathrm{MgSO} 4$ [pH 7.0]). The yeast cell pellets were lysed via freeze-thaw cycles. All reactions were initiated by the addition of Z-buffer (containing $\beta$-mercaptoethanol and $4 \mathrm{mg} / \mathrm{mL}$ ONPG) to the samples. The reactions were incubated at $30{ }^{\circ} \mathrm{C}$ for $30 \mathrm{~min}$ and then stopped by adding chilled $1 \mathrm{M} \mathrm{Na}_{2} \mathrm{CO}_{3}$ for the development of yellow color. Absorbance was measured at $420 \mathrm{~nm}$ [31], and $\beta$-Gal activity was calculated according to the following formula:

$$
\beta-\text { Gal activity }=\frac{A_{420}}{\left(T \times V \times A_{600}\right)} \times 1000
$$

where $T$ is the time of reaction ( $\mathrm{min}$ ) and $V$ is the volume of culture used in the assay $(\mathrm{mL})$.

\subsection{Subcellular Localization Analysis and Bimolecular Fluorescence Complementation (BiFC) Assay}

To conduct subcellular localization analysis, the open reading frames (ORFs) of TaF$B X L, T a G P I-A P$, and TaABP1 were cloned into a pMDC43 vector [29] using LR clonase 
(Thermo Fisher Scientific, Waltham, MA, USA) to generate N-terminal fusions with the enhanced green fluorescent protein (GFP) gene. The resulting plasmids, 35S:GFP-TaFBXL, 35S:GFP-TaGPI-AP, and 35S:GFP-TaABP1 were introduced into Agrobacterium tumefaciens strain GV3101 using the freeze-thaw method. The transformed GV3101 cells harboring 35S:GFP-TaFBXL and 35S:GFP-TaGPI-AP were grown in Luria-Bertani medium until the $\mathrm{OD}_{600}$ of the culture reached 1.0. The cells were harvested by centrifugation at $5000 \times g$ for $10 \mathrm{~min}$ at room temperature, and the cell pellets were resuspended in infiltration buffer (10 mM MES, $10 \mathrm{mM} \mathrm{MgCl}$, and $200 \mathrm{mM}$ acetosyringone [pH 5.6]). The Agrobacterium cell suspension was infiltrated into tobacco (Nicotiana benthamiana) leaves using a syringe.

To conduct the BiFC assay, the ORFs of TaFBXL, TaGPI-AP, and TaABP1 were cloned into the destination vectors pGTQL1211-YN (GFP-N) or pGTQL1221-YC (GFP-C) using the Gateway system [29]. Then, all constructs were introduced into A. tumefaciens strain GV3101 and infiltrated into tobacco leaves, as previously described [32]. Fluorescence in tobacco leaves was detected at $72 \mathrm{~h}$ post-infiltration (hpi) using a confocal laser-scanning microscope (Zeiss LSM800, Oberkochen, Germany).

\subsection{MG132 Treatment and Western Blot Analysis}

A. tumefaciens GV3101 carrying the 35S:GFP-TaGPI-AP construct was infiltrated into the leaves of 4 -week-old tobacco ( $N$. benthamiana) plants and incubated at $22{ }^{\circ} \mathrm{C}$ for $48 \mathrm{~h}$. To perform proteasome inhibitor treatments, leaves of independent tobacco plants were injected with $50 \mu \mathrm{M}$ MG132 and sprayed with $100 \mu \mathrm{M}$ IAA. Tobacco (N. benthamiana) leaves were collected at $0,3,6$, and $12 \mathrm{hpi}$, and total protein was extracted from the leaves using the protein extraction buffer (Elpis Biotech, Daejeon, Korea). The protein concentration was determined using the Bradford Assay Kit (Takara, Shiga, Japan). To perform Western blot, the protein concentrations of all samples were adjusted to $0.5 \mu \mathrm{g} / \mu \mathrm{L}$, following which $5 \mu \mathrm{g}$ of total extracted proteins from tobacco leaves were separated on $12 \%$ acrylamide gel using sodium dodecyl sulfate-polyacrylamide gel electrophoresis (SDS-PAGE) and then transferred onto nitrocellulose membranes using the iBlot 2 Dry Blotting System (Thermo Fisher Scientific, Waltham, MA, USA). Membranes were incubated with rabbit anti-GFP antibody (primary antibody; Abcam, Cambridge, UK). Then, HRP-conjugated goat antirabbit antibody (secondary antibody; Thermo Fisher Scientific, Waltham, MA, USA) was used as a secondary antibody to generate the light signal. The membrane was visualized using Amersham ECL Western Blotting Detection Reagent (GE Healthcare, Chicago, IL, USA), and chemiluminescence was recorded using the iBright CL1000 Imaging System (Invitrogen, Waltham, MA, USA).

\section{Results}

\subsection{TaFBXL Isolation and RNA Accumulation Patterns}

The TaFBXL gene (TraesCS1B02G275600) was isolated from wheat seedling cDNA, based on the wheat reference genome sequence provided by the International Wheat Genome Sequencing Consortium. The TaFBXL ORF was 1062 bp in size and was predicted to encode a 379-aa protein (Table S2). The amino acid sequence of TaFBXL was analyzed by the Simple Modular Architecture Research Tool (SMART) to identify and annotate the protein domains and to analyze the protein domain architecture [33]. TaFBXL consisted of one F-box domain at the N terminus (SMART accession: SM000256), five Leu-rich repeat domains (SMART accession: SM000370), and three Leu-rich repeat, cysteine (Cys)-containing domains (SMART accession: SM000367) (Figure 1A and Table S3). Then, the expression of TaFBXL was analyzed by RT-qPCR in wheat seedlings at different developmental stages including leaf at Z13 (three leaves emerged; Stage 1), leaf at Z24 (main stem and four tillers; Stage 2), leaf at Z51 (leaf at the tip of ear just visible, booting stage; Stage 3), spikelets at Z61 (beginning of anthesis; Stage 4), spikelets at Z73 (early milk development; Stage 5), spikelets at Z83 (early dough; Stage 6), and spikelets at Z91 (hard grain; Stage 7) (Figure 1B). TaFBXL showed high expression during vegetative growth (Figure 1C). 
(A)

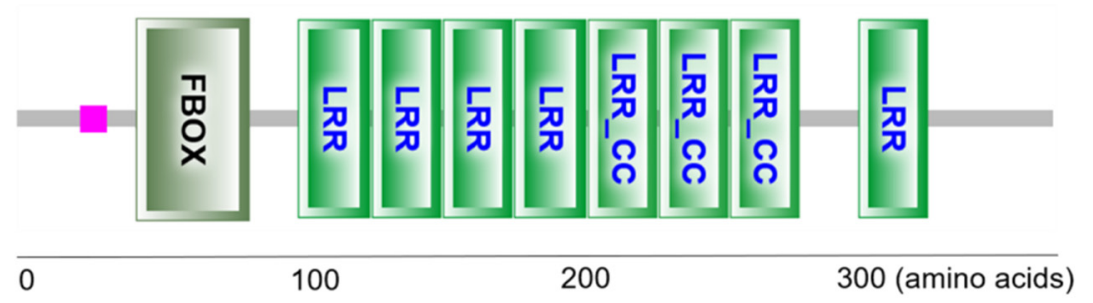

(B)

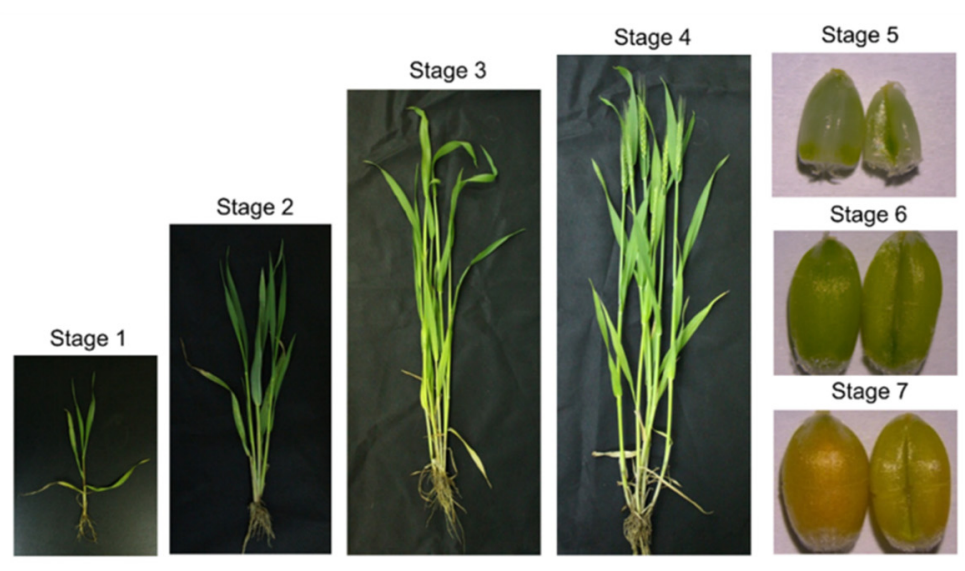

(C)

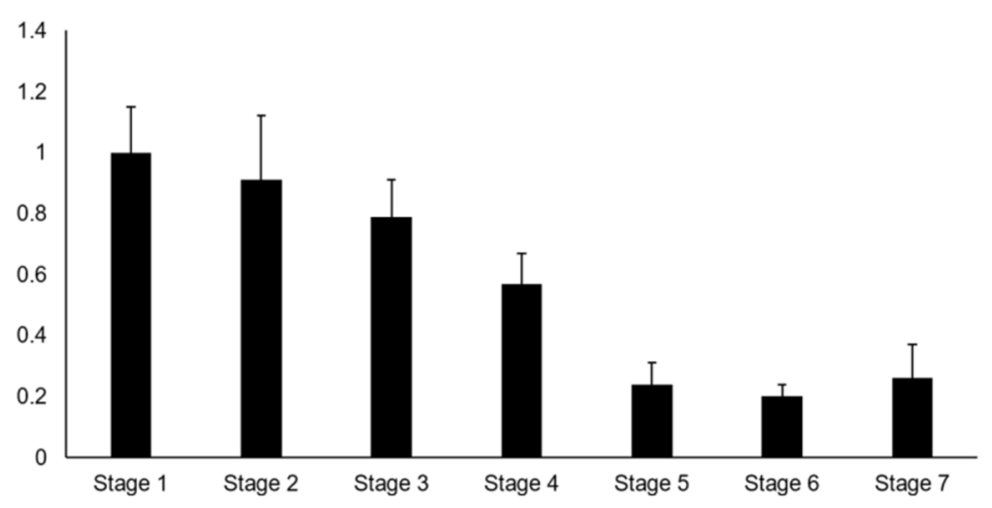

Figure 1. Analysis of the TaFBXL protein structure and TaFBXL gene expression: (A) domain structure of TaFBXL. Domains identified by the hidden Markov model algorithms of SMART or PFam include F-box motif, leucine-rich repeats (LRR), and leucine-rich repeat and cysteine-containing (LRR_CC) motif; (B) images showing different developmental stages of wheat used for reverse transcription-quantitative polymerase chain reaction (RT-qPCR). Stage 1, leaf at Z13 (three emerged leaves); Stage 2, leaf at Z24 (main stem and four tillers); Stage 3, leaf at Z51 (leaf at tip of ear just visible, booting stage); Stage 4, spikelets at Z61 (beginning of anthesis); Stage 5, spikelets at Z73 (early milk development); Stage 6, spikelets at Z83 (early dough); Stage 7, spikelets at Z91 (hard grain); (C) transcript levels of TaFBXL at seven different developmental stages of wheat, determined by RT-qPCR. RT-qPCR was performed with three biological replicates, and each bar represents mean \pm SD for average $n=3$ independent experiments.

\subsection{TaFBXL Is a Component of the SCF Complex}

The SCF ubiquitin-protein ligase is an E3 ligase, and the F-box protein is linked to the core complex through its interaction with Skp1, which is important for protein ubiquitination [34]. Previous reports demonstrated that wheat F-box proteins interact with SKP1-like protein to form an SCF complex $[35,36]$. To confirm that TaFBXL protein is a component of the SCF complex, we tested direct interaction between TaFBXL and TaSKPs by performing $\mathrm{Y} 2 \mathrm{H}$ assays. The TaFBXL gene was fused with the GAL4 DNAbinding domain in the pGBKT7 vector (bait), and six TaSKP sequences were fused to 
the activation domain of GAL4 in the pGADT7 vector. All interactions between TaFBXL and TaSKPs were tested on the DDO/X/A medium after co-transformation (Figure 2A), whereas only two combinations of TaFBXL and TaSKPs were grown on the QDO/X/A medium (Figure 2B). TaFBXL showed interaction with TaSKP1 and TaSKP6. Then, the $\beta$-Gal assay was performed to quantify the relative intensity of the protein-protein interactions. Consistent with the results of the $\mathrm{Y} 2 \mathrm{H}$ assay, the $\beta-\mathrm{Gal}$ activities of TaFBXL-TaSKP1 and TaFBXL-TaSKP6 interactions were 28.4 and 34.0 units, respectively (Figure 2C).

(A)

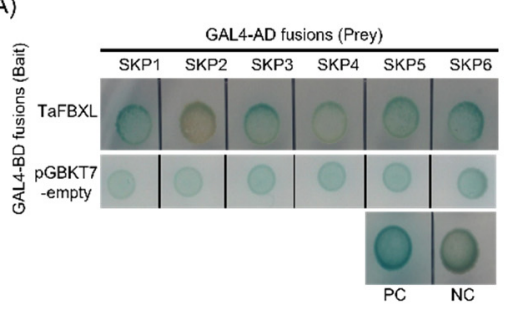

(B)

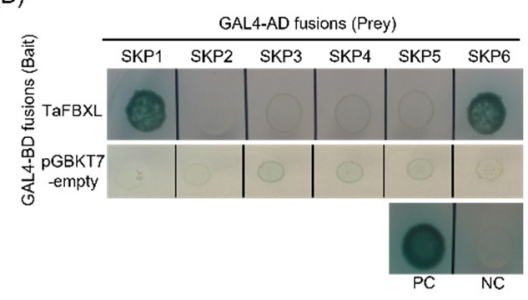

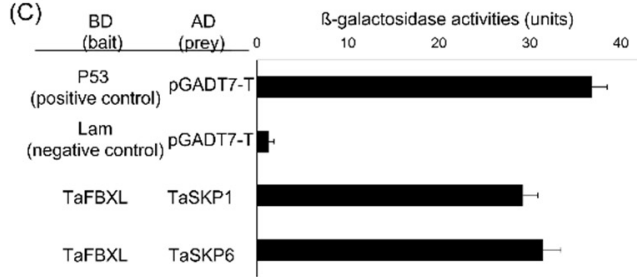

Figure 2. Analysis of interactions between TaFBXL and TaSKP by yeast two-hybrid assays: (A,B) co-transformants grown on SD/-Leu/-Trp (A) or SD/-Ade/-His/-Leu/-Trp (B) medium supplemented with X- $\alpha$-Gal. SV40 large T antigen (pGADT7T)/p53 (pGBKT7-53) and SV40 large T antigen (pGADT7-T)/Lamin-C (pGBKT7-Lam) were used as positive (PC) and negative controls (NC), respectively. The pGBKT7-empty vector was also used as negative control; (C) strength of TaFBXLTaSKP interactions measured by performing $\beta$-Gal assays using 2-nitrophenyl $\beta$-D-galactopyranoside as a substrate. Each bar represents mean \pm SD for average $n=3$ independent experiments.

\subsection{TaFBXL Interacts with TaGPI-AP}

$\mathrm{Y} 2 \mathrm{H}$ assays were performed using the wheat seedling cDNA library to identify proteins that interact with TaFBXL. Approximately, $3.87 \times 10^{7}$ transformants were tested, and 50 positive clones were identified in two consecutive rounds of testing (first round: DDO, second round: QDO $+\mathrm{X}-\alpha-\mathrm{Gal})$. These were amplified by colony PCR and sequenced. Among them, only six proteins were characterized after exclusion of the false positives and out-of-frame clones. Six clones were selected based on BLASTX alignment of their deduced amino acid sequences (Table 1). For further analysis, co-transformation of TaFBXL and full-length TaFBXL-interacting proteins was performed. Among the putative binding partners of TaFBXL, GPI-AP was found to be a highly reliable positive candidate. This study mainly focuses on GPI-AP, which plays key roles in a wide variety of biological processes occurring at the interface of the plasma membrane and cell wall, such as signaling, cell wall metabolism, cell wall polymer cross-linking, and plasmodesmatal transport [23,37]. To validate the interaction between TaFBXL and TaGPI-AP, yeast co-transformation assay was conducted with the combinations of pGBKT7:TaFBXL and pGADT7:TaGPI-AP, and its reciprocal interaction was assessed by the combination of pGBKT7:TaGPI-AP and pGADT7:TaFBXL. The results of co-transformation assays confirmed the interaction between TaFBXL and TaGPI-AP, as yeast colonies showed growth on QDO/X/A media in both combinations (Figure $3 \mathrm{~A}$ ). Consistent with these results, strong $\beta$-Gal activity was detected in both co-transformation assays (Figure 3B).

Table 1. List of TaFBXL-interacting protein candidates identified by yeast two-hybrid assays and BLASTX results searched from NCBI NR (nonredundant) database.

\begin{tabular}{cccc}
\hline Clone No. & Putative Identification & Organism & $e$-Value \\
\hline 25,28 & WESR2 (wheat early salt-stress responding gene 2) & Triticum aestivum & 0.00 \\
\hline 34 & Signal recognition particle 9-kDa protein & Aegilops tauschii & 0.00 \\
\hline 38 & Chlorophyll a-b binding protein of LHCII type 1 & Aegilops tauschii & 0.00 \\
\hline 42 & 40S ribosomal protein S3a & Aegilops tauschii & 0.00 \\
\hline 45 & Glycosylphosphatidylinositol (GPI)-anchored & Aegilops tauschii & 0.00 \\
\hline
\end{tabular}


(A)

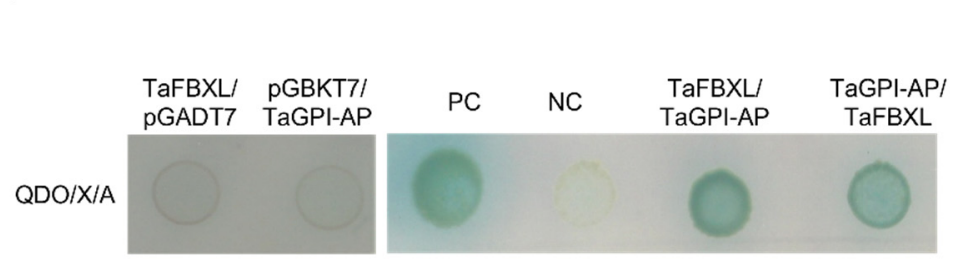

(B)

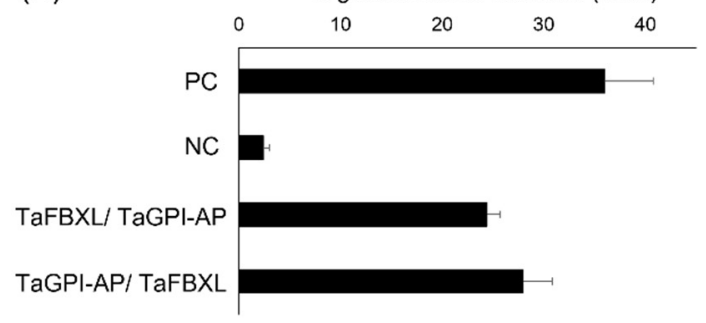

Figure 3. Interaction between TaFBXL and TaGPI-AP determined by yeast two-hybrid (Y2H) assays: (A) results of the Y2H assay showing the interaction between TaFBXL and TaGPI-AP; (B) quantification of the strength of interaction between TaFBXL and TaGPI-AP by performing the $\beta$-Gal assay. The experiments were performed in triplicates. Error bars indicate \pm SD of three independent experiments. PC: positive control (pGBKT7-p53/pGADT7-T), NC: negative control (pGBKT7Lam/pGADT7-T). The pGADT7-empty or pGBKT7-empty vector was also used as negative controls (left panel). Each bar represents mean $\pm \mathrm{SD}$ for average $n=3$ independent experiments.

\subsection{Subcellular Localization and Interaction between TaFBXL and TaGPI-AP}

To explore the biological function of TaFBXL and TaGPI-AP, we investigated the subcellular localization of these proteins. Vectors carrying GFP:TaFBXL and GFP:TaGPI-AP GFP:TaABP1 fusions were constructed and then agroinfiltrated into tobacco (N. benthamiana) leaves. The fluorescence signal of GFP:TaFBXL was detected in the nucleus and plasma membrane (Figure 4A), whereas that of GFP:TaGPI-AP was observed in the cytosol and probably also the plasma membrane. To examine the interaction between TaFBXL and TaGPI-AP in plants, we performed BiFC assays. TaFBXL was fused to the N-terminal fragment of GFP (EGFP-N) to generate the pGTQL1211-TaFBXL construct, while TaGPI-AP was fused to the C-terminal fragment of GFP (EGFP-C) to generate the pGTQL1221-TaGPI$\mathrm{AP}$ construct. The BiFC assay revealed an interaction between TaFBXL and TaGPI-AP in the nucleus and plasma membrane (Figure 4B).

\subsection{TaGPI-AP Interacts with TaABP1}

A previous study indicated that a GPI-AP protein named CBP1 interacts with ABP1 in maize [24]. To demonstrate the role of TaGPI-AP as a membrane-bound docking protein combined with ABP1, we confirmed the interaction between TaGPI-AP and TaABP1 proteins using $\mathrm{Y} 2 \mathrm{H}$ and $\mathrm{BiFC}$ assays. The interaction between TaGPI-AP and TaABP1 was confirmed by yeast co-transformation analysis (Figure 5A). TaABP1 localized to the cytosol and probably also plasma membrane (Figure 5B), and weak interaction was detected between TaGPI-AP and TaABP1 in the plasma membrane via the BiFC assay (Figure 5C). 
(A)

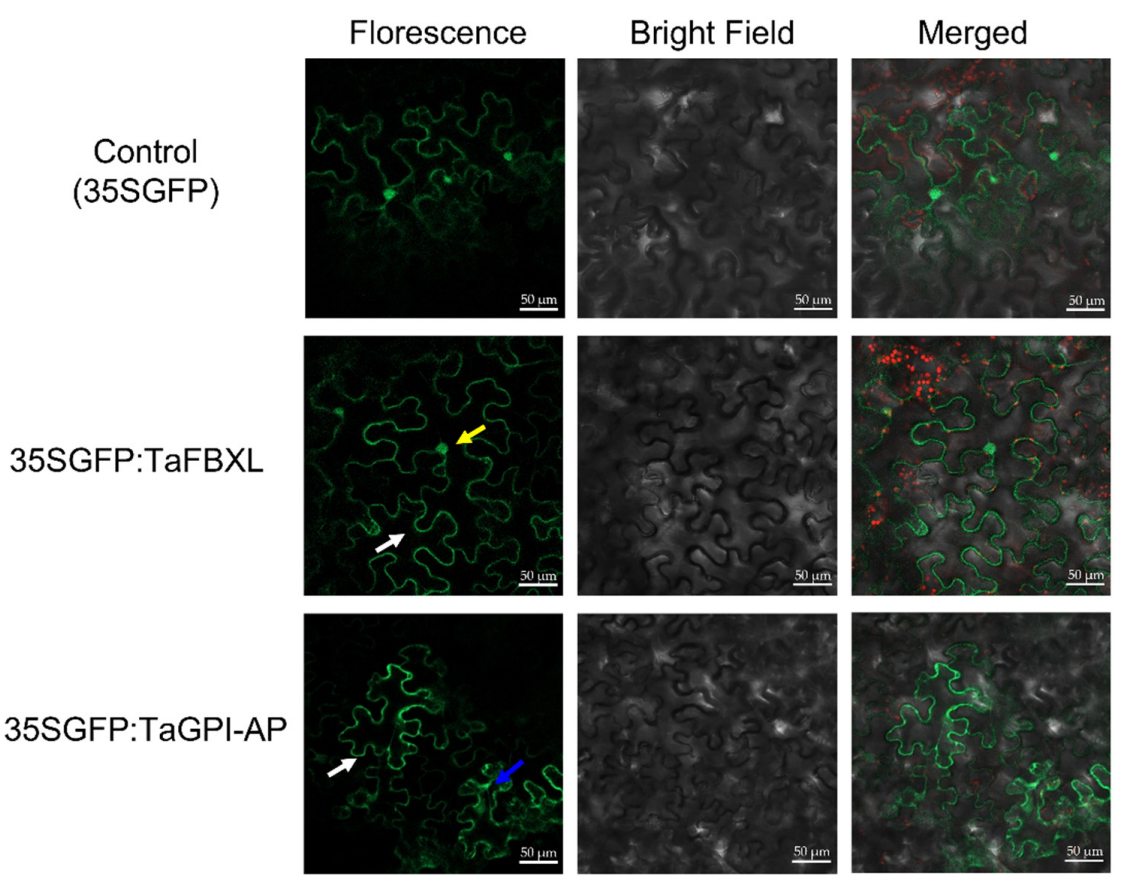

(B)

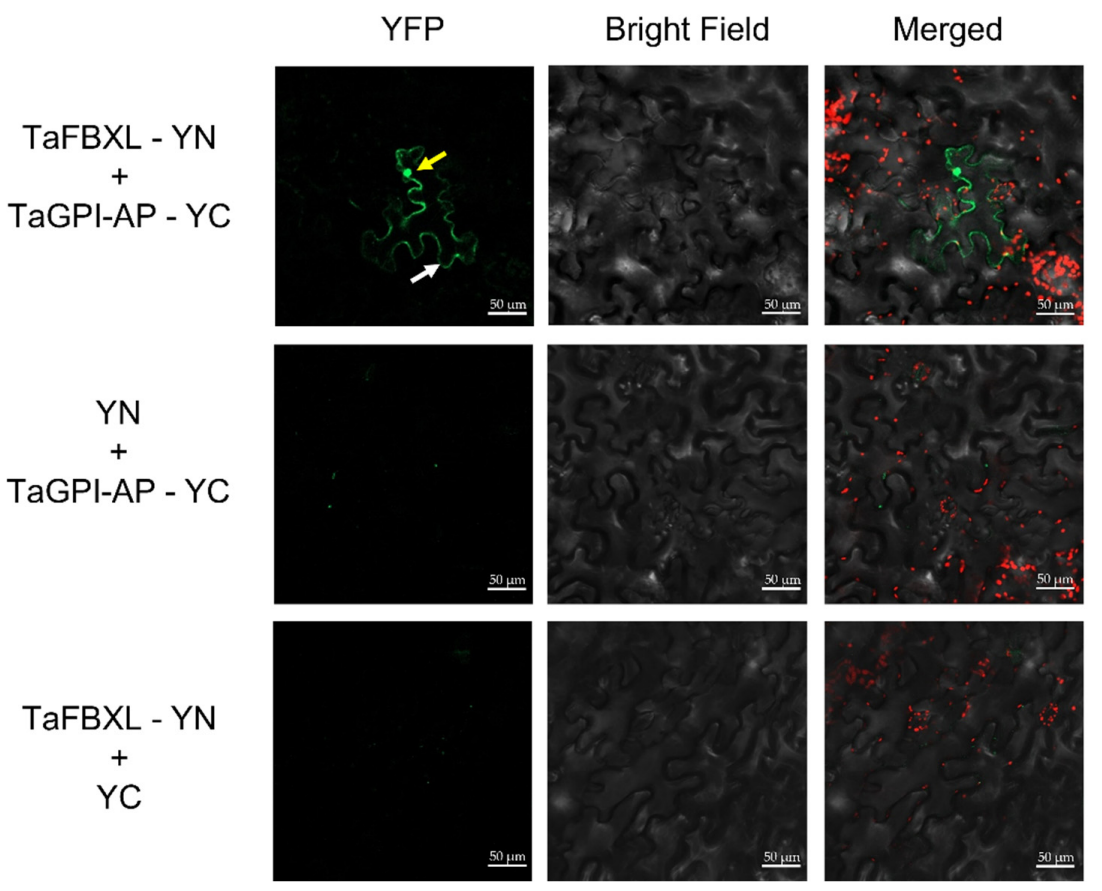

Figure 4. Analysis of the subcellular localization of GFP:TaFBXL and GFP:TaGPI-AP fusion proteins and the interaction between these proteins: (A) subcellular localization of GFP:TaFBXL and GFP:TaGPIAP fusion proteins visualized by confocal microscopy. Tobacco ( $N$. benthamiana) leaf epidermal cells were infiltrated with A. tumefaciens carrying the GFP:TaFBXL fusion construct driven by the 35 S promoter. Yellow arrow: nucleus, white arrows: plasma membrane, blue arrow: cytosol; (B) results of the bimolecular fluorescence complementation assay used to detect the interaction between TaFBXL and TaGPI-AP in agroinfiltrated tobacco (N. benthamiana) leaves. Yellow arrow: nucleus, white arrow: plasma membrane. YN, N-terminal region of GFP; YC, C-terminal region of GFP. 
(A)

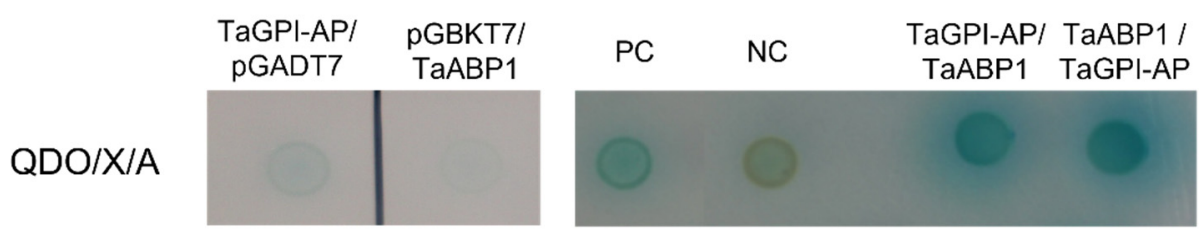

(B)

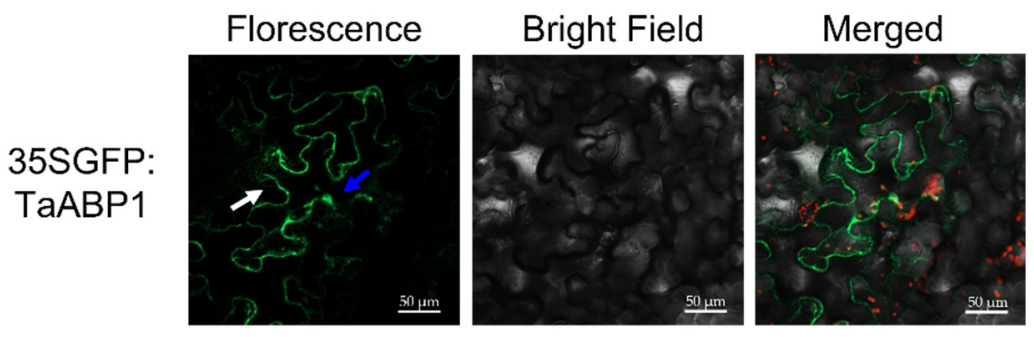

(C)

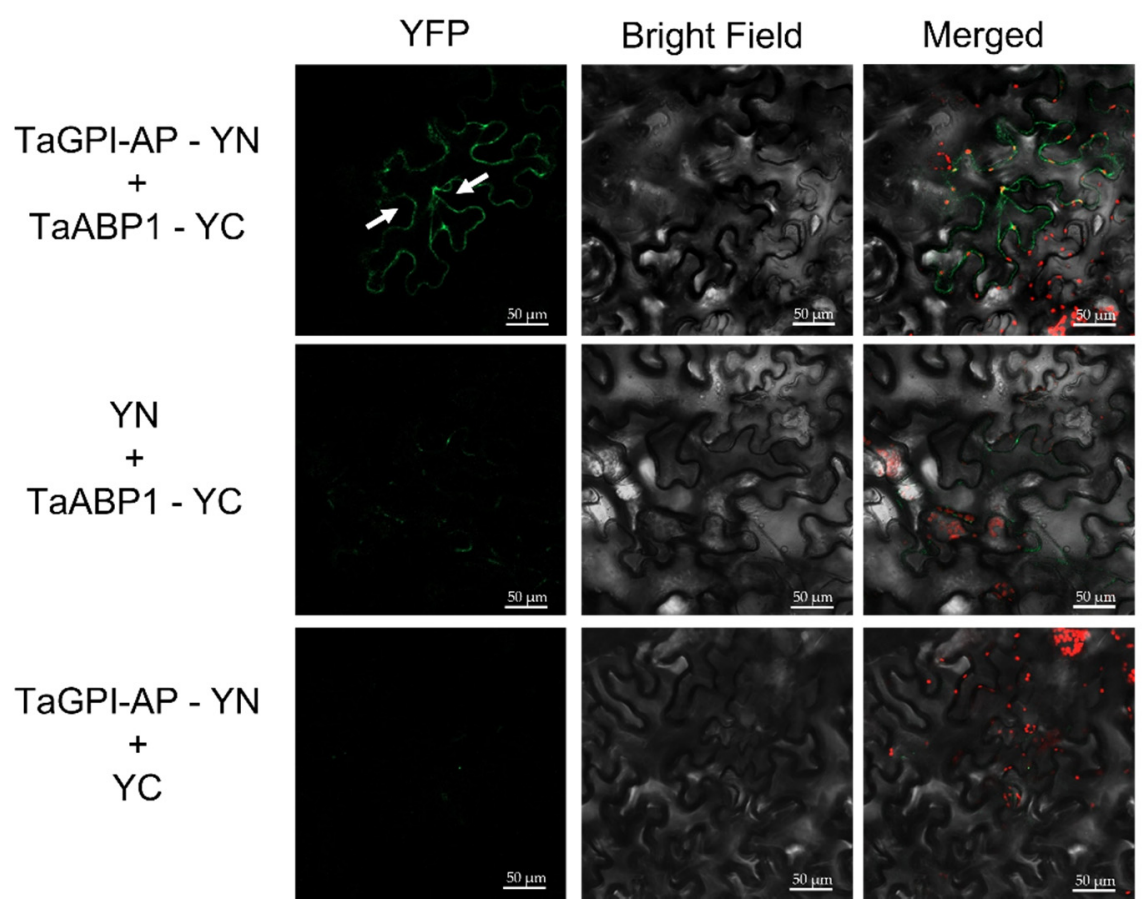

Figure 5. Analysis of the interaction between TaGPI-AP and TaABP1 by yeast two-hybrid (Y2H) and bimolecular fluorescence complementation (BiFC) assays: (A) results of the $\mathrm{Y} 2 \mathrm{H}$ assay showing the interaction between TaGPI-AP and TaABP1. PC: positive control (pGBKT7-p53/pGADT7-T), NC: negative control (pGBKT7-Lam/pGADT7-T). The pGADT7-empty or pGBKT7-empty vector was also used as negative controls (left panel); (B) subcellular localization of 35SGFP:TaABP1. Confocal images of tobacco (N. benthamiana) leaf epidermal cells expressing the GFP fusion of TaABP1 are shown. White arrow: plasma membrane, blue arrow: cytosol; (C) interaction between TaGPI-AP and TaABP1 proteins in the BiFC assay. TaGPI-AP fused to the N-terminal YFP, and TaABP1 fused into the C-terminal YFP. White arrows: plasma membrane.

\subsection{Degradation of TaGPI-AP in $26 S$ Proteasome}

To determine whether TaGPI-AP is degraded by the $26 \mathrm{~S}$ proteasome in vivo, total proteins were extracted from tobacco ( $N$. benthamiana) leaves infiltrated with A. tumefaciens in the presence or absence of MG132 (proteasome inhibitor). Western blotting with an anti-GFP antibody was used to validate the production of the foreign protein. The level of TaGPI-AP in leaves treated with MG132 was higher than that in leaves not treated with MG132 at the same point (Figure 6A). Previous studies showed that GPI-AP interacts with 
the C-terminus of ABP1 to facilitate the secretion of auxin by providing a docking position on the cell membrane to ABP1 [38]. Therefore, we evaluated the effect of IAA treatment on the RNA accumulation patterns of TaFBXL and TaGPI-AP and on the levels of the encoded proteins. TaFBXL and TaGPI-AP showed opposite RNA accumulation patterns under the IAA treatment; when TaFBXL was downregulated, TaGPI-AP was upregulated and vice versa (Figure 6B). Consistent with the results shown in Figure 6A, the level of TaGPI-AP was enhanced by treatment with the 26S proteasome inhibitor, MG132. In the absence of MG132, the accumulation of TaGPI-AP was reduced compared with DMSO-treated samples at the same time point. A higher accumulation of TaGPI-AP was found in samples treated with both, MG132- and IAA, than in samples treated with either MG132 or IAA (Figure 6C).

(A)

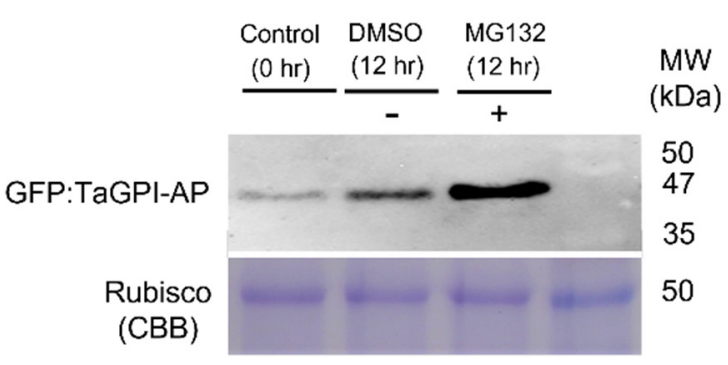

(B)

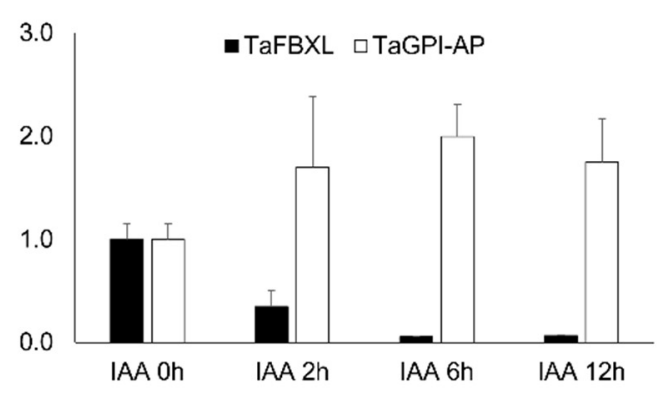

(C)

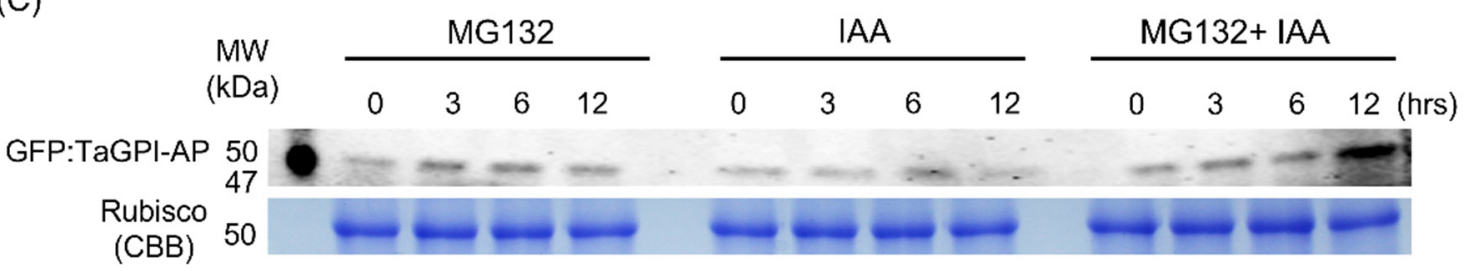

Figure 6. Inhibition of protein degradation by $26 \mathrm{~S}$ proteasome in plants: (A) Western blot analysis using total protein extracted from transiently transformed tobacco (N. benthamiana) leaves expressing GFP:TaGPI-AP and treated with (+) or without (-) $50 \mu \mathrm{M}$ MG132. The GFP:TaGPI-AP protein was detected using an anti-GFP antibody. Coomassie Brilliant Blue (CBB) staining was used to verify the amount of protein loaded; (B) RNA accumulation patterns of TaFBXL and TaGPI-AP under indole-3-acetic acid (IAA) treatment using RT-qPCR. Seedlings with fully expanded 3rd leaf were collected at $0,2,6$, and $12 \mathrm{~h}$ after treatment with $100 \mu \mathrm{mol}$ IAA. RT-qPCR was performed with three biological replicates. Each bar represents the mean \pm SD of three independent experiments $(n=3) ;(C)$ Western blot analysis of protein extracts prepared from transiently transformed tobacco (N. benthamiana) leaves expressing GFP:TaGPI-AP treated with $50 \mu \mathrm{M}$ MG132. CBB indicates the CBB staining of Rubisco's large subunit as a loading control in $5 \mu \mathrm{g}$ of total protein.

\section{Discussion}

Many members of the F-box gene family are induced by intracellular signals, environmental changes, and abiotic and biotic stress conditions [39]. The diverse expression patterns of a large number of F-box genes suggest that these genes play diverse roles in plant growth and development and in the response to cellular and extracellular cues [40]. Most F-box proteins studied to date participate in the recognition of target proteins for ubiquitination and $26 \mathrm{~S}$ proteasome-mediated protein degradation as a component of the SCF complex [41]. FBX proteins contain an F-box motif at the $\mathrm{N}$ terminus and diverse $\mathrm{C}$ terminal domains, such as LRR, Kelch, WD-40, Armadillo (Arm), tetratricopeptide repeats (TPRs), Tub, actin, DEAD-like helicase, and jumonji (JmjC), which recognize the target protein [42]. FBXL is a large subfamily of the plant FBX family, and 160, 61, and 46 FBXLs have been identified in Arabidopsis, rice, and maize, respectively [14,39,42]. Previous studies showed that plant FBXLs mediate target protein degradation in response to developmental and hormonal signals $[43,44]$. In addition, LRR domains identified at the C-terminus of TaFBXL constitute a domain superfamily found in animals, yeast, protists, bacteria, and 
plants. The LRR domain is characterized by the presence of tandem repeats of 18-29-aa long Leu-rich motif [45]. Although LRRs are found in diverse proteins, their function is highly conserved across plant species; LRRs provide a platform for specific protein-protein interactions [46] and are critical for protein function, as they are involved in either ligand recognition or docking to other components of the pathway [47]. However, the function of FBXL in wheat remains largely unknown.

To investigate the function of FBXL in wheat, we isolated the CDS of the TaFBXL gene from the cDNA of wheat seedlings. Sequence analysis revealed that TaFBXL contains a conserved F-box domain at the $\mathrm{N}$ terminus and eight LRRs at the $\mathrm{C}$ terminus, which are potentially involved in the recognition of the target protein (Figure 1A and Table 1). We confirmed the interaction between TaFBXL and TaSKPs, thus validating that the $\mathrm{N}$ terminus of the F-box domain interacts with TaSKPs, resulting in the formation of the SCF complex for $26 \mathrm{~S}$ proteasome-mediated ubiquitination of the target protein. TaFBXL showed strong interaction with TaSKP1 and TaSKP6 (Figure 2), indicating that TaFBXL possessing F-box domain interacted with TaSKPs as a component of the SCF complex. The previous reports identified the putative F-box genes and six TaSKPs in wheat and showed protein-protein interactions between F-box proteins and TaSKPs to verify whether they are the components of wheat SCF complexes $[30,35,36]$. Interestingly, F-box proteins did not interact with all TaSKPs and showed different interaction patterns. Although all deduced TaSKPs contained an SKP1 component and POZ domain (IPR016073, InterProScan), TaSKP1 and TaSKP6 showed the greatest similarity with 97\% identical residues, while TaSKP2 showed lower conservation at the amino acid sequence level (less than $35 \%$ identical residues), compared with other TaSKPs [36]. The variance of sequence composition may influence differently on both interactions of TaSKPs with F-box protein and protein functions.

IAA plays a crucial role in the regulation of a wide range of plant growth and developmental processes [48]. In the last few decades, ABPs have been identified and proposed to play a key role in auxin perception at the plasma membrane [19,49]. ABP1 localizes to the plasma membrane, where it mediates rapid electrophysiological and cell physiological responses to auxin [50] and acts as a modulator of clathrin-mediated endocytosis and microtubule orientation through its action on the ROP family of GTPases [51,52]. GPI-APs mediates the posttranslational glycolipid modification of numerous cell surface proteins in eukaryotes [53]. GPI biosynthesis starts with a lipid molecule at the rough side of the ER triggered by a hydrophobic signal sequence of GPI-AP at the C terminus. GPI-AP is further modified in the ER and Golgi apparatus, that hydrophobic signal at the $C$ terminus is cleaved at the $\omega$ position and replaced by various types of glycans and lipids for remodeling. After various maturation steps, GPI-AP is transported to the cell membrane [53-55]. Interestingly, maize GPI-AP, named CBP1, directly interacts with extracellular auxin by binding to $\mathrm{ABP} 1$, and the $\mathrm{CBP} 1-\mathrm{ABP} 1$ complex is recognized by the cell surface reporter, TMM1, leading to a quick auxin response $[23,56,57]$. Consistent with previous reports, we showed that TaGPI-AP localizes to the plasma membrane and that TaFBXL localizes to the nucleus and plasma membrane. Moreover, our BiFC and yeast co-transformation assays showed that TaGPI-AP interacts with TaABP1 at the plasma membrane.

However, the role of ABP1 in auxin signaling has remained controversial, and its mode of action remains unclear. The abp1 null alleles generated using the CRISPR-Cas technology showed indistinguishable phenotypes during flowering and did not show a strong or rapid response to auxin in the plasma membrane of wild-type plants [58]. In addition, studies showed that membrane depolarization and endocytosis inhibition are ABP1-independent responses, and auxin-induced plasma membrane depolarization is dependent on the auxin influx carrier AUX1 [59]. On the other hand, the Arabidopsis GPI-AP protein participates in various biological processes, such as signal transduction by associating with cell surface receptors and/or extracellular ligands, developmental processes, and stress and immune responses [39]. Arabidopsis GPI-AP (SKU5) with auxinrelated extracellular protein-ligand ABP1 could be recognized by the cell surface receptor kinase TMK1 and activate intracellular signaling components [60]. Furthermore, GPI- 
AP (SKU5) loss of function redundantly and drastically inhibited seed production and integument/seed coat development [60].

In this study, under IAA treatment, the RNA accumulation patterns of TaFBXL were downregulated, whereas those of TaGPI-AP were upregulated (Figure 6B). It is assumed that increased TaGPI-AP mRNA levels result in increased translation to form TaGPI-AP, which could interact with extracellular auxin by binding to ABP1 for exogenous auxin response. The decreased RNA accumulation of TaFBXL under exogenous IAA treatment results presumably in lower TaFBXL protein levels, thereby possibly leading to increased TaGPI-AP protein levels. TaGPI-AP is not degraded by the $26 \mathrm{~S}$ proteasome in the presence of MG132, which effectively blocks the proteolytic activity of the $26 \mathrm{~S}$ proteasome complex (Figure 6A). In addition, the level of TaGPI-AP was increased following MG132 treatment, which was a result of the inhibition of the $26 \mathrm{~S}$ proteasome system. Therefore, it is assumed that the different levels of TaGPI-AP between MG132- and IAA-treated samples were a result of the difference in the amount of degradation via the $26 \mathrm{~S}$ proteasome. Consistent with this hypothesis, more accumulation of TaGPI-AP was detected in both MG132and IAA-treated samples than in MG132- or IAA-treated samples (Figure 6C). The RNA accumulation of TaGPI-AP is upregulated by exogenous auxin application, and degradation of TaGPI-AP could possibly be reduced by decreasing the abundance of TaFBXL through the $26 \mathrm{~S}$ proteasome system. This could lead to the accumulation of TaGPI-AP in the cell, thus enabling TaGPI-AP and the auxin-related extracellular receptor ABP1 to recognize exogenous auxin. Altogether, our study suggests that TaGPI-AP is degraded by the ubiquitin-proteasome system in plant cells, and TaFBXL acts as a potential regulator of TaGPI-AP in the presence of exogenous auxin to facilitate the signal transduction of the ABP-based cell surface receptor complex.

Supplementary Materials: The following are availble online at https:/ / www.mdpi.com/article/10 .3390 / plants10081606/s1, Table S1. The information of primers used in this study. Table S2. The CDS and peptide sequence of the TaFBXL gene. Table S3. High-confidence domains and repeats in the TaFBXL protein.

Author Contributions: Conceptualization, D.Y.K. and M.J.H.; formal analysis, M.J.H.; investigation, M.J.H.; funding acquisition, J.-B.K.; methodology, D.Y.K. and M.J.H.; writing-original draft preparation, M.J.H. and D.Y.K.; writing-review and editing, J.-B.K. and Y.W.S.; supervision, D.Y.K. All authors have read and agreed to the published version of the manuscript.

Funding: This work was supported by grants from the Nuclear R\&D Program of the Ministry of Science and ICT (MSIT) and the research program of KAERI, Republic of Korea.

Institutional Review Board Statement: Not applicable.

Informed Consent Statement: Not applicable.

Conflicts of Interest: The authors declare no conflict of interest.

\section{References}

1. Sharma, B.; Joshi, D.; Yadav, P.K.; Gupta, A.K.; Bhatt, T.K. Role of ubiquitin-mediated degradation system in plant biology. Front. Plant Sci. 2016, 7, 806. [CrossRef]

2. Dielen, A.S.; Badaoui, S.; Candresse, T.; German-Retana, S. The ubiquitin/26S proteasome system in plant-pathogen interactions: A never-ending hide-and-seek game. Mol. Plant Pathol. 2010, 11, 293-308. [CrossRef]

3. Kraft, E.; Stone, S.L.; Ma, L.; Su, N.; Gao, Y.; Lau, O.S.; Deng, X.W.; Callis, J. Genome analysis and functional characterization of the E2 and RING-type E3 ligase ubiquitination enzymes of Arabidopsis. Plant Physiol. 2005, 139, 1597-1611. [CrossRef]

4. Vierstra, R.D. The ubiquitin-26S proteasome system at the nexus of plant biology. Nat. Rev. Mol. Cell Biol. 2009, 10, 385. [CrossRef]

5. Chen, L.; Hellmann, H. Plant E3 ligases: Flexible enzymes in a sessile world. Mol. Plant 2013, 6, 1388-1404. [CrossRef]

6. Gray, W.M.; Hellmann, H.; Dharmasiri, S.; Estelle, M. Role of the Arabidopsis RING-H2 protein RBX1 in RUB modification and SCF function. Plant Cell 2002, 14, 2137-2144. [CrossRef]

7. Xu, G.; Ma, H.; Nei, M.; Kong, H. Evolution of F-box genes in plants: Different modes of sequence divergence and their relationships with functional diversification. Proc. Natl. Acad. Sci. USA 2009, 106, 835-840. [CrossRef] [PubMed] 
8. Majee, M.; Kumar, S.; Kathare, P.K.; Wu, S.; Gingerich, D.; Nayak, N.R.; Salaita, L.; Dinkins, R.; Martin, K.; Goodin, M. KELCH F-BOX protein positively influences Arabidopsis seed germination by targeting PHYTOCHROME-INTERACTING FACTOR1. Proc. Natl. Acad. Sci. USA 2018, 115, E4120-E4129. [CrossRef] [PubMed]

9. Wang, G.M.; Yin, H.; Qiao, X.; Tan, X.; Gu, C.; Wang, B.H.; Cheng, R.; Wang, Y.Z.; Zhang, S.L. F-box genes: Genome-wide expansion, evolution and their contribution to pollen growth in pear (Pyrus bretschneideri). Plant Sci. 2016, 253, 164-175. [CrossRef] [PubMed]

10. Bu, Q.; Lv, T.; Shen, H.; Luong, P.; Wang, J.; Wang, Z.; Huang, Z.; Xiao, L.; Engineer, C.; Kim, T.H. Regulation of drought tolerance by the F-box protein MAX2 in Arabidopsis. Plant Physiol. 2014, 164, 424-439. [CrossRef]

11. Zhao, Z.; Zhang, G.; Zhou, S.; Ren, Y.; Wang, W. The improvement of salt tolerance in transgenic tobacco by overexpression of wheat F-box gene TaFBA1. Plant Sci. 2017, 259, 71-85. [CrossRef]

12. Abel, S.; Oeller, P.W.; Theologis, A. Early auxin-induced genes encode short-lived nuclear proteins. Proc. Natl. Acad. Sci. USA 1994, 91, 326-330. [CrossRef] [PubMed]

13. Song, J.B.; Wang, Y.X.; Li, H.B.; Li, B.W.; Zhou, Z.S.; Gao, S.; Yang, Z.M. The F-box family genes as key elements in response to salt, heavy mental, and drought stresses in Medicago truncatula. Funct. Integr. Genomic. 2015, 15, 495-507. [CrossRef]

14. Jia, Q.; Xiao, Z.X.; Wong, F.L.; Sun, S.; Liang, K.J.; Lam, H.M. Genome-wide analyses of the soybean F-box gene family in response to salt stress. Int. J. Mol. Sci. 2017, 18, 818. [CrossRef] [PubMed]

15. Dill, A.; Thomas, S.G.; Hu, J.; Steber, C.M.; Sun, T. The Arabidopsis F-box protein SLEEPY1 targets gibberellin signaling repressors for gibberellin-induced degradation. Plant Cell 2004, 16, 1392-1405. [CrossRef]

16. Kepinski, S.; Leyser, O. The Arabidopsis F-box protein TIR1 is an auxin receptor. Nature 2005, 435, 446-451. [CrossRef] [PubMed]

17. Binder, B.M.; Walker, J.M.; Gagne, J.M.; Emborg, T.J.; Hemmann, G.; Bleecker, A.B.; Vierstra, R.D. The Arabidopsis EIN3 binding F-Box proteins EBF1 and EBF2 have distinct but overlapping roles in ethylene signaling. Plant Cell 2007, 19, 509-523. [CrossRef]

18. Villalobos, L.I.A.C.; Lee, S.; De Oliveira, C.; Ivetac, A.; Brandt, W.; Armitage, L.; Sheard, L.B.; Tan, X.; Parry, G.; Mao, H. A combinatorial TIR1/AFB-Aux/IAA co-receptor system for differential sensing of auxin. Nat. Chem. Biol. 2012, 8, 477. [CrossRef]

19. Hertel, R.; Thomson, K.S.; Russo, V. In-vitro auxin binding to particulate cell fractions from corn coleoptiles. Planta 1972, 107, 325-340. [CrossRef]

20. Löbler, M.; Klämbt, D. Auxin-binding protein from coleoptile membranes of corn (Zea mays L.): I. Purification by immunological methods and characterization. J. Biol. Chem. 1985, 260, 9848-9853. [CrossRef]

21. Robert, S.; Kleine-Vehn, J.; Barbez, E.; Sauer, M.; Paciorek, T.; Baster, P.; Vanneste, S.; Zhang, J.; Simon, S.; Čovanová, M. ABP1 mediates auxin inhibition of clathrin-dependent endocytosis in Arabidopsis. Cell 2010, 143, 111-121. [CrossRef] [PubMed]

22. Chen, J.; Yang, Z. Novel ABP1-TMK auxin sensing system controls ROP GTPase-mediated interdigitated cell expansion in Arabidopsis. Small GTPases 2014, 30, e29711. [CrossRef]

23. Shimomura, S. Identification of a glycosylphosphatidylinositol-anchored plasma membrane protein interacting with the Cterminus of auxin-binding protein 1: A photoaffinity crosslinking study. Plant Mol. Biol. 2006, 60, 663-677. [CrossRef] [PubMed]

24. Shi, J.H.; Yang, Z.B. Is ABP1 an auxin receptor yet? Mol. Plant 2011, 4, 635-640. [CrossRef]

25. Hong, M.J.; Kim, J.-B.; Seo, Y.W.; Kim, D.Y. F-box genes in the wheat genome and expression profiling in wheat at different developmental stages. Genes 2020, 11, 1154. [CrossRef]

26. Zadoks, J.C.; Chang, T.T.; Konzak, C.F. A decimal code for the growth stages of cereals. Weed Res. 1974, 14, 415-421. [CrossRef]

27. Cai, T.; Meng, X.; Liu, X.; Liu, T.; Wang, H.; Jia, Z.; Yang, D.; Ren, X. Exogenous hormonal application regulates the occurrence of wheat tillers by changing endogenous hormones. Front. Plant Sci. 2018, 9, 1886. [CrossRef] [PubMed]

28. Su, P.; Yan, J.; Li, W.; Wang, L.; Zhao, J.; Ma, X.; Wang, H.; Kong, L. A member of wheat class III peroxidase gene family, TaPRX-2A, enhanced the tolerance of salt stress. BMC Plant Biol. 2020, 20, 392. [CrossRef]

29. Curtis, M.D.; Grossniklaus, U. A gateway cloning vector set for high-throughput functional analysis of genes in planta. Plant Physiol. 2003, 133, 462-469. [CrossRef]

30. Hong, M.J.; Kim, D.Y.; Choi, H.; Seo, Y.W.; Kim, J.-B. Isolation and characterization of kelch repeat-containing F-box proteins from colored wheat. Mol. Biol. Rep. 2020, 47, 1129-1141. [CrossRef]

31. Miller, J. Assay of B-Galactosidase: Experiments in Molecular Genetics; Cold Spring Harbor Laboratory Press: Long Island, NY, USA, 1972.

32. Walter, M.; Chaban, C.; Schütze, K.; Batistic, O.; Weckermann, K.; Näke, C.; Blazevic, D.; Grefen, C.; Schumacher, K.; Oecking, C. Visualization of protein interactions in living plant cells using bimolecular fluorescence complementation. Plant J. 2004, 40, 428-438. [CrossRef]

33. Letunic, I.; Bork, P. 20 years of the SMART protein domain annotation resource. Nucleic Acids Res. 2018, 46, D493-D496. [CrossRef] [PubMed]

34. Hermand, D. F-box proteins: More than baits for the SCF? Cell Div. 2006, 1, 30. [CrossRef] [PubMed]

35. Hong, M.J.; Kim, D.Y.; Kang, S.Y.; Kim, D.S.; Kim, J.B.; Seo, Y.W. Wheat F-box protein recruits proteins and regulates their abundance during wheat spike development. Mol. Biol. Rep. 2012, 39, 9681-9696. [CrossRef] [PubMed]

36. Hong, M.J.; Kim, D.Y.; Seo, Y.W. SKP1-like-related genes interact with various F-box proteins and may form SCF complexes with Cullin-F-box proteins in wheat. Mol. Biol. Rep. 2013, 40, 969-981. [CrossRef] [PubMed]

37. Yeats, T.H.; Bacic, A.; Johnson, K.L. Plant glycosylphosphatidylinositol anchored proteins at the plasma membrane-cell wall nexus. J. Integr. Plant Biol. 2018, 60, 649-669. [CrossRef] 
38. Zhou, K. Glycosylphosphatidylinositol-anchored proteins in Arabidopsis and one of their common roles in signaling transduction. Front. Plant Sci. 2019, 10, 1022. [CrossRef]

39. Jain, M.; Nijhawan, A.; Arora, R.; Agarwal, P.; Ray, S.; Sharma, P.; Kapoor, S.; Tyagi, A.K.; Khurana, J.P. F-box proteins in rice. Genome-wide analysis, classification, temporal and spatial gene expression during panicle and seed development, and regulation by light and abiotic stress. Plant Physiol. 2007, 143, 1467-1483. [CrossRef] [PubMed]

40. Zhang, X.; Gonzalez-Carranza, Z.H.; Zhang, S.; Miao, Y.; Liu, C.J.; Roberts, J.A. F-Box Proteins in Plants. Annu. Plant Rev. 2018, 2, $1-21$.

41. Kipreos, E.T.; Pagano, M. The F-box protein family. Genome Biol. 2000, 1, 1-7. [CrossRef] [PubMed]

42. Gagne, J.M.; Downes, B.P.; Shiu, S.H.; Durski, A.M.; Vierstra, R.D. The F-box subunit of the SCF E3 complex is encoded by a diverse superfamily of genes in Arabidopsis. Proc. Natl. Acad. Sci. USA 2002, 99, 11519-11524. [CrossRef]

43. Hellmann, H.; Estelle, M. Plant development: Regulation by protein degradation. Science 2002, 297, 793-797. [CrossRef] [PubMed]

44. Kuroda, H.; Takahashi, N.; Shimada, H.; Seki, M.; Shinozaki, K.; Matsui, M. Classification and expression analysis of Arabidopsis F-box-containing protein genes. Plant Cell Physiol. 2002, 43, 1073-1085. [CrossRef] [PubMed]

45. Kajava, A. Structural diversity of leucine-rich repeat proteins. J. Mol. Biol. 1998, 277, 519-527. [CrossRef]

46. Kobe, B.; Kajava, A.V. The leucine-rich repeat as a protein recognition motif. Curr. Opin. Struct. Biol. 2001, 11, 725-732. [CrossRef]

47. Forsthoefel, N.R.; Cutler, K.; Port, M.D.; Yamamoto, T.; Vernon, D.M. PIRLs: A novel class of plant intracellular leucine-rich repeat proteins. Plant Cell Physiol. 2005, 46, 913-922. [CrossRef] [PubMed]

48. Teale, W.D.; Paponov, I.A.; Palme, K. Auxin in action: Signalling, transport and the control of plant growth and development. Nat. Rev. Mol. Cell Biol. 2006, 7, 847-859. [CrossRef]

49. Löbler, M.; Klämbt, D. Auxin-binding protein from coleoptile membranes of corn (Zea mays L.): II. Localization of a putative auxin receptor. J. Biol. Chem. 1985, 260, 9854-9859. [CrossRef]

50. Napier, R.M.; David, K.M.; Perrot-Rechenmann, C. A short history of auxin-binding proteins. Plant Mol. Biol. 2002, 49, 339-348. [CrossRef]

51. Chen, X.; Naramoto, S.; Robert, S.; Tejos, R.; Löfke, C.; Lin, D.; Yang, Z.; Friml, J. ABP1 and ROP6 GTPase signaling regulate clathrin-mediated endocytosis in Arabidopsis roots. Curr. Biol. 2012, 22, 1326-1332. [CrossRef] [PubMed]

52. Chen, X.; Grandont, L.; Li, H.; Hauschild, R.; Paque, S.; Abuzeineh, A.; Rakusová, H.; Benkova, E.; Perrot-Rechenmann, C.; Friml, J. Inhibition of cell expansion by rapid ABP1-mediated auxin effect on microtubules. Nature 2014, 516, 90-93. [CrossRef]

53. Kinoshita, T. Glycosylphosphatidylinositol (GPI) anchors: Biochemistry and cell biology: Introduction to a thematic review series. J. Lipid Res. 2016, 57, 4-5. [CrossRef]

54. Stevens, V.L. Biosynthesis of glycosylphosphatidylinositol membrane anchors. Biochem. J. 1995, 310, 361. [CrossRef] [PubMed]

55. Eisenhaber, B.; Bork, P.; Eisenhaber, F. Sequence properties of GPI-anchored proteins near the omega-site: Constraints for the polypeptide binding site of the putative transamidase. Protein Eng. 1998, 11, 1155-1161. [CrossRef]

56. Xu, T.; Dai, N.; Chen, J.; Nagawa, S.; Cao, M.; Li, H.; Zhou, Z.; Chen, X.; De Rycke, R.; Rakusová, H. Cell surface ABP1-TMK auxin-sensing complex activates ROP GTPase signaling. Science 2014, 343, 1025-1028. [CrossRef] [PubMed]

57. Cao, M.; Chen, R.; Li, P.; Yu, Y.; Zheng, R.; Ge, D.; Zheng, W.; Wang, X.; Gu, Y.; Gelová, Z. TMK1-mediated auxin signalling regulates differential growth of the apical hook. Nature 2019, 568, 240-243. [CrossRef]

58. Gao, Y.; Zhang, Y.; Zhang, D.; Dai, X.; Estelle, M.; Zhao, Y. Auxin binding protein 1 (ABP1) is not required for either auxin signaling or Arabidopsis development. Proc. Natl. Acad. Sci. USA 2015, 112, 2275-2280. [CrossRef]

59. Paponov, I.A.; Dindas, J.; Król, E.; Friz, T.; Budnyk, V.; Teale, W.; Paponov, M.; Hedrich, R.; Palme, K. Auxin-induced plasma membrane depolarization is regulated by auxin transport and not by AUXIN BINDING PROTEIN1. Front. Plant Sci. 2019, 9, 1953. [CrossRef] [PubMed]

60. Zhou, K.; Fiume, E.; De-Vos, D.; Magnani, E. GPI-anchored SKU5/SKS are maternally required for integument development in Arabidopsis. Genome Biol. 2000. 